UDC 811. 811.161

\title{
THE CONCEPT MODERN LIFE IN MODERN UKRAINIAN LINGUACULTURE
}

\author{
Olha Ladyka, \\ Ternopil Volodymyr Hnatiuk National Pedagogical University, \\ Ternopil, Ukraine \\ olha.ladyka@gmail.com \\ Oksana Yarema, \\ Ternopil Volodymyr Hnatiuk National Pedagogical University, \\ Ternopil, Ukraine \\ oksana.yarema.05@gmail.com
}

Received March, 19, 2020; Accepted May, 07, 2020

\begin{abstract}
In this article, consideration is given to the investigation of the meaning and peculiarities of the semantic structure of the linguacultural concept MODERN LIFE functioning in modern Ukrainian worldview. Linguacultural concept is treated as a multi-layered mental formation in culture that organizes the knowledge of a certain fragment of reality in the consciousness of a certain language and cultural community. Linguacultural concept accumulates knowledge about a certain fragment of reality in the collective consciousness of a certain national language and cultural community, it is objectified by its linguistic form and marked by language and cultural specifics. The concept MODERN LIFE plays an important role in the life of every civilized man. Its significance for Ukrainian culture is grounded because it serves as one of the most important key phrases with high emotional intensity and broad associative field. Aiming to determine the main lexical means that stand for the investigated concept this research demonstrates the strong connection between language and culture and their influence on each other.

The article focuses on the peculiarities of the free association experiment and the receptive experiment. Associative experiment allows to reconstruct the relations of language units in the language consciousness of native speakers and to specify the peculiarities of the occurrence of these units in language consciousness. The advantage of this method is also reflected in the fact that it can reveal more distinctive features of the concept, and through the frequency of reactions to define the relevance of these features in language consciousness. The receptive experiment aims at discovering the specifics of understanding and perception of a concept, its subjective definition. It allows obtaining more information about the understanding of specific units in the process of concept verbalization. Moreover, by application of receptive and associative experiments the article aims at specifying the thematic fields in the semantic representation of the concept. The interpretation of experimental data, allowing to specify the meanings associated with the concept in the minds of Ukrainian native speakers provides the analysis of semantic modifications caused by social and political events in Ukrainian realis, history and society. Receptive and associative experiments were held with 87 Ukrainian speaking students, graduate students (81 females and 6 males) at Foreign Languages Department of Ternopil Volodymyr Hnatiuk National Pedagogical University, Ukraine. The respondents' age was from 18 to 22.

With the help of the free word association test the connections of the concept MODERN LIFE in the Ukrainian language consciousness and the semantic zones of this stimulus phrase were determined. Psycholinguistic ideas about modern life in Ukraine are manifested in the ambivalence of the components, the semantic clues of which are "technology/gadgets", "internet/online" and "communication". Qualitative analysis of the results of the free word association test helped to build the respondents' images of modern Ukrainian hallmarks (borshch, EuroMaydan / Maidan and war). The
\end{abstract}


linguacultural concept MODERN LIFE functioning in modern Ukrainian worldview bears negative connotation. Next, we subtracted the highest and lowest values displayed above the group of bars and made comparison between the with the reference to results, the tallest vertical bar for the value The essential components of this concept are "self-confidence" and very close to it is "strong family".

Thus, the benefits of the methods of the experimental study of the concepts in the study of the features of the national worldview are stated in the research.

Key words: modern life, concept, analysis, interpretation, language culture, worldview, receptive experiment.

\section{Introduction}

This research is an attempt to demonstrate a strong connection among a language, culture, and conceptualization. It is done in the field of linguistic culturology (or cultural linguistics). Theoretical stances regarding this theme have ranged from a view that language shapes human thought and world-view to one that considers the three to be separate systems. Cultural Linguistics, with its multidisciplinary origin, engages with this theme by exploring features of human languages that encode culturally constructed conceptualisations of human experience. Interdisciplinary researches gain more popularity as by showing the interrelation of different spheres of a human and their functioning in the world helps to get deeper into human cognition, world understanding and the essence of living (Sharifian, 2017: 54). Combining the findings and methods of cognitive linguistics, linguistic anthropology, ethnography enables a researcher to explore cultural models, which are associated with the use of language. At the present stage of the development of linguistics the notion of a concept occupies an important place. It is an integral part of consciousness and the language worldview. Nowadays language and cultural concepts are being studied, because they reflect ethnic and sociocultural norms, language mentality of a certain ethnic group and combine people's knowledge about the world, their experience, their understanding of reality. They are mediators between cultures.

The problem of interaction between culture and language turns to be quite relevant in our time, and therefore the linguacultural concept occupies an important place. Modern linguistics after long discussions, theories and researches takes it as a fact that the relationship between language and culture is deeply rooted. Language is used to maintain and convey culture and cultural ties. A human perceives the world not through separated information units but through concepts that establish meanings in the mind. The process of conceptualization of the surrounding world lies in the idea that human reason captures the structures of inner representation of the world by means of language, because language is the main representative of the cognitive structures. Y. Stepanov (Stepanov, 2001: 43) argues that the structure of the concept contains all its constituent meanings, and, in addition, the structure of the concept includes everything that makes it a fact of culture - the original form, condensed content of history, modern associations, evaluations, etc. Consequently, the linguacultural concept is fixed by language means of expression and stored as a mental concept in the native speakers' consciousness (Skliarenko, 2018: 302). Thus, being a unit of consciousness, the concept is difficult to get direst access to, so scientist have to deal with language material that represents concepts in a particular language. Numerous works of scientists are devoted to linguocultural concept and its 
research, namely the investigations by S. Askoldov, A. Babushkin, S. Vorkachov, V. Vorobyov, V. Karasik, Z. Popova, V. Telia, E. Kubriakova, G. Slishkin, I. Sternin, Y. Stepanov, I. Golubovska, O. Ladyka, A. Prikhodko, I. Shevchenko, V. Kozlovskyi, O. Skliarenko, O. Petiak, D. Terekhova, T. Khomulenko, A. Kuznetsov and others.

The concept MODERN LIFE brings a lot of material to be discussed as it covers many areas of real life taking place in a certain location, culture, religion, political, economical, ecological, etc. situation. The concept LIFE is a universal, as every culture has the idea of life and the relevant language means of expressing it (Bobro, 2020: 12-13). Through universal concepts certain norms of behavior and a system of rules of relationships are expressed. "Universals ideally are generalizations that capture properties <...> that are essential to and stable across all possible languages" (Siemund, 2011: 1). Linguacultural universals being fundamental human concepts that form a common conceptual basis for the development of different cultures, their thinking and languages (Wierzbicka, 1997). In different parts of the world life is infinitely diverse. The mentality and cultural values of people can vary greatly, and even be the exactly opposite. Each ethnic group lives in the world made up of customs and traditions, which find expression in the peculiarities of behavior, religion, social and cultural values and norms. People relate differently to each other, there is no person with the same lifestyle as everyone perceives the world differently: such notions as experience, failure, success, happiness, hatred, love, money, hospitality, beauty, anger, friendship, knowledge, memory, honesty, etc. are perceived and understood by people very specifically and individually. Due to certain circumstances and factors, the existing stereotypes contribute to the formation of the unique private world, unique form of consciousness by every particular individual. It is this personal space and general patterns of social relations that constitute the culture of the people. Nevertheless, different nations, different cultures have some specific features of life perception.

The concept LIFE in national worldviews has been studied on the data of various languages: Ukrainian, English, German, Spanish, Latin, Russian, Chinese and others. These investigation deals with the structure of the concept; the mythological ideas that form the basis of some cultural connotations; the poetic images that describe MODERN LIFE and the metaphoric representation of the concept (Blyzniuk, 2008; Krasnobaeva-Chorna, 2008; Kuz'menko, 2016; Ladyka, 2017). The studies of the concept LIFE in Ukrainian linguoculture are mainly based on phraseology or paroemias. The particular research aspects include Ukrainian national stereotypes and their correlation within the social, temporal and existential thematic groups (Ivanova, 2008); the ideographic structure of the concept, its associative complex and connection with microconcepts like soul, fate and others (Krasnobaeva-Chorna, 2008); the archetypes and gestalts that reflect life perception (Blyzniuk, 2008); the representation of the concept LIFE in Ukrainian national language worldview by universal images (Bobro, 2020).

However, the concept LIFE is such a broad, all-encompassing phenomenon that there still are aspects that have not been fully studied. The components of the concept MODERN LIFE as representing the concept LIFE in its modern interpretation in Ukrainian linguoculture have not yet become the object of language studies. Including new material to the research also helps to reveal some data that has not as yet been paid attention to. The aim of the present article is to describe the features of the image 
representation of the concept MODERN LIFE in language worldview of Ukrainian people. The study is based on psycholinguistic experimental data.

Associative experiment allows to reconstruct the relations of language units in the language consciousness of native speakers and to specify the peculiarities of the occurrence of these units in language consciousness. It enables the revealing of mental lexicon, verbal memory and cultural stereotypes of the nation. The methodological effectiveness of associative experiment for studying vocabulary has been proved by some authors (Leontiev, 2003; Kubrjakova, 2005; Khomulenko, Kuznetsov, 2019). Associative experiment assists in revealing the concept substance in cognitive consciousness of native speakers and defining of the concept formation. The core of language consciousness includes those associations of verbal associative network that have the largest number of links identified on the basis of a frequency principle (Slobodyan, 2009). According to A. Leontiev (Leontiev, 2003:10), associative norms can be used as a source of unique linguistics and paralinguistic information, and also they are easily processed mathematically, being a unique material for proposing and testing statistical hypotheses. The results of associative experiment provide meaningful data on the impact of gender, age, professional specificity in the understanding of the meaning of lexical item that represent culturesignificant concepts. The advantage of this method is also reflected in the fact that it can reveal more distinctive features of the concept, and through the frequency of reactions to define the relevance of these features in language consciousness. The receptive experiment aims at discovering the specifics of understanding and perception of a concept, its subjective definition. It allows obtaining more information about the understanding of specific units in the process of concept verbalization. Thus, the collected results give a definite idea of the concept's main features and provide information concerning the ethno-specific features of reality perception by the people who speak the given language.

\section{Materials and methods}

The purpose of our research is the psycho-semantic reconstruction of the linguacultural concept MODERN LIFE semantic field. The study of the linguacultural concept MODERN LIFE functioning in modern Ukrainian worldview was conducted during December 2019 - December 2020 on the basis of Ternopil Volodymyr Hnatiuk National Pedagogical University, Foreign Languages Department (Ternopil). The receptive experiment was conducted in the written form. The total number of respondents who took part in the experiment was 87 people (aged 18-22), all Ukrainians by their nationality. Among them, there were 81 females and 6 males, $96.6 \%$ and $3.4 \%$ accordingly. The respondents were informed about the anonymous character of the survey and the possibility to resign on any stage.

The objective of the study was also to test and verify the effectiveness of the scientific hypothesis. The latter was that in the national cognitive sphere of young Ukrainians concept MODERN LIFE should include the following features: modern life is associated with technologies and Internet, this concept bears negative connotation, COVID-19 occupies a substantial part of it, wealth and family are dominating parts of the concept structure.

To receive efficient results of receptive and associative experiments, we 
created a two-part questionnaire. The first part contained "introductory" questions (university group and age) necessary to define the age and social group of the research objects. The second part contained five stages where the respondents had to: 1. indicate the first and the only word-association which come to their mind as a response to the "Modern Life" phrase-stimulus; 2. write down first five reactions which come to their mind as a response to "modern time living" expression; 3. put down the first word you think of after reading the phrase "Modern Ukrainian Realia"; 4. answer a question if the meaning of the phrase "Modern Ukrainian Realia" is more negative or positive to their mind; 5. decide if the provided components are essential, important but not essential, or not important to their own view of the "Modern Life Concept". When interpreting the results of free word association test and other questions of the questionnaire, the received data was consolidated to define the semantic core of the associations.

The word association test (WAT) is an important tool of semantic research (Lat. associato -combination, experimentum - experience), which is widely used to study the peculiarities of comprehension and recognition of the concepts used by the speakers and it provides "live" data to build associative fields of certain concepts, to reconstruct fragments of language and conceptual worldview (Malimon, Pashkina, 2019: 60). We have used the modified version of the "Sentence Completion" method which refers to projective diagnostics and is a variation of the Word Associations technique. It is considered that the associations received present both reportable and unconscious attitudes of a person to the perception of certain concepts or phenomena (Petrenko, 2005; Petiak, 2020). The associative method represents cognitive structures behind language meanings, individual peculiarities of the examined and their personal senses (Abdikalyk et al., 2016; Lozova, 2007; Malimon, Pashkina, 2019; Terekhova, 2018).

During the fifth stage of the experimental study the method of semantic differential was applied. This psycholinguistic method lies in a combination of the method of controlled associations and scaling procedures, has become an experimental method of personal meaning system reconstruction and individual and group semantic spaces of the concept MODERN LIFE construction (Petrenko, 2005; Lozova, 2007; Malimon, Pashkina, 2019).

The experiment was carried out in written form and it complicated spontaneous response but contributed to the respondents' personal experience actualization.

\section{Results and discussions}

Five stages of the questionnaire together make up a system of main lexical means that stand for the investigated concept MODERN LIFE.

I. As a result of the first stage of WAT, 120 words-associations have been received, which outlined the semantic field of responses on the phrase-stimulus. Processing of the results has been carried out using the method of ranking the words given by the examined according to the frequency of the representation: association responses given more than three times have been considered to be an association norm; primary (nuclear) and secondary (peripheral) associations have been analysed.

Table 1 shows the results of the first stage of the study (WAT). 
Results of word association test

\begin{tabular}{|l|c|}
\hline \multicolumn{2}{|c|}{$\begin{array}{c}\text { Associative responses of respondents } \\
\text { to the phrase-stimulus the "Modern Life" }\end{array}$} \\
\hline \multicolumn{1}{|c|}{ Reaction } & Amount (\%) \\
\hline Technology/gadgets & 44.4 \\
\hline Internet / online & 14.8 \\
\hline Communication & 7.4 \\
\hline Style & 3.7 \\
\hline Rapid pace & 3.7 \\
\hline Entertainment & 3.7 \\
\hline Integration & 3.7 \\
\hline Culture & 3.7 \\
\hline Tolerance & 3.7 \\
\hline Society & 3.7 \\
\hline Changes & 3.7 \\
\hline Digitalization & 3.7 \\
\hline
\end{tabular}

The fact that technology (44.4\%), the Internet (14.8\%) and communication (7.4\%) scored the highest percentage indicates that:

1. our present and future are based on technologies, online tools and search engines and this is already an integral part of our modern life;

2. an average Ukrainian man needs the Internet for development, learning, work and entertainment today;

3. communication is important for people, and with the help of the Internet and gadgets it can be done even at a distance.

II. The results obtained from the first and second stages of the word association test research show that the concept MODERN LIFE is associated with social media $(16.5 \%)$, the Internet $(10.1 \%)$, gadgets $(8.9 \%)$, technology $(7.3 \%)$, digitalization $(5.6 \%)$, money (5.3\%), COVID-19 (4.6\%), traveling (2.5\%), timemanagement $(2.25 \%)$, globalization $(1.9 \%)$, development $(1.8 \%)$, opportunity $(1.3 \%)$ and freedom $(1.3 \%)$. A group of respondents believe that modern life provides pollution (1.45\%) and fast food consumption (1.35\%), is about setting a business $(1.5 \%)$, and provokes freelance $(1.45 \%)$. Respondents wrote also the following associations with the stimulus "modern time living" (that occupy periphery zone as are not common): personal characteristics and feelings, such as loneliness $(1.0 \%)$, selfimprovement $(0.8 \%)$, tolerance $(0.8 \%)$, achievements $(0.8 \%)$, independence $(0.8 \%)$, individualism $(0.7 \%)$, solitude $(0.7 \%)$, uncertainty $(0.7 \%)$, quick decision making $(0.7 \%)$, sympathy $(0.6 \%)$, values $(0.5 \%)$, creativity $(0.5 \%)$. Thus, we may find the connection between the first stage core reactions like "technology/gadgets", "internet/online" and the second-stage associations "social media" that have direct ties with each other. The first serves as a tool for the second as an object.

The political issues were also included, namely: Trump $(0.6 \%)$, scary political games $(0.4 \%)$, black lives matter $(0.7 \%)$, imperialism $(0.5 \%)$. Economical realis were present in the responses: Elon Mask $(0.5 \%)$, machinery $(0.4 \%)$, consumption $(0.4 \%)$. We define a separate group of associations connected with modern education and distance learning especially: education ( $0.4 \%)$, high quality education $(0.4 \%)$, studying 
$(0.4 \%)$, zoom $(0.5 \%)$, Moodle $(0.4 \%)$. We explain this by the fact that our target group was comprised by students for whom education is occupying major part of their interests and time. The associations Googling $(0.6 \%)$, blogging $(0.8 \%)$, FOMO $(0.9 \%)$, memes $(0.6 \%)$ are connected with online communication. $1.4 \%$ of respondents mention "delivery" in terms of a possibility of getting anything bought and delivered to any part of the country. Among associations with negative connotation we should mention radiation $(0.4 \%)$, overpopulation $(0.4 \%)$, alienation $(0.5 \%)$, phubbing $(0.4 \%)$, not prioritizing $(0.4 \%)$, noise $(0.35 \%)$. It was unexpected to determine the opposites: healthy lifestyle $(0.5 \%)$ and need of health $(0.4 \%)$.

With the help of a visualization method, namely word cloud technique that allows representing the frequency of the words graphically, the given results with the top words are shown a those with greater prominence and those descending in size to the periphery were mentioned to a lesser extent (Fig. 1).

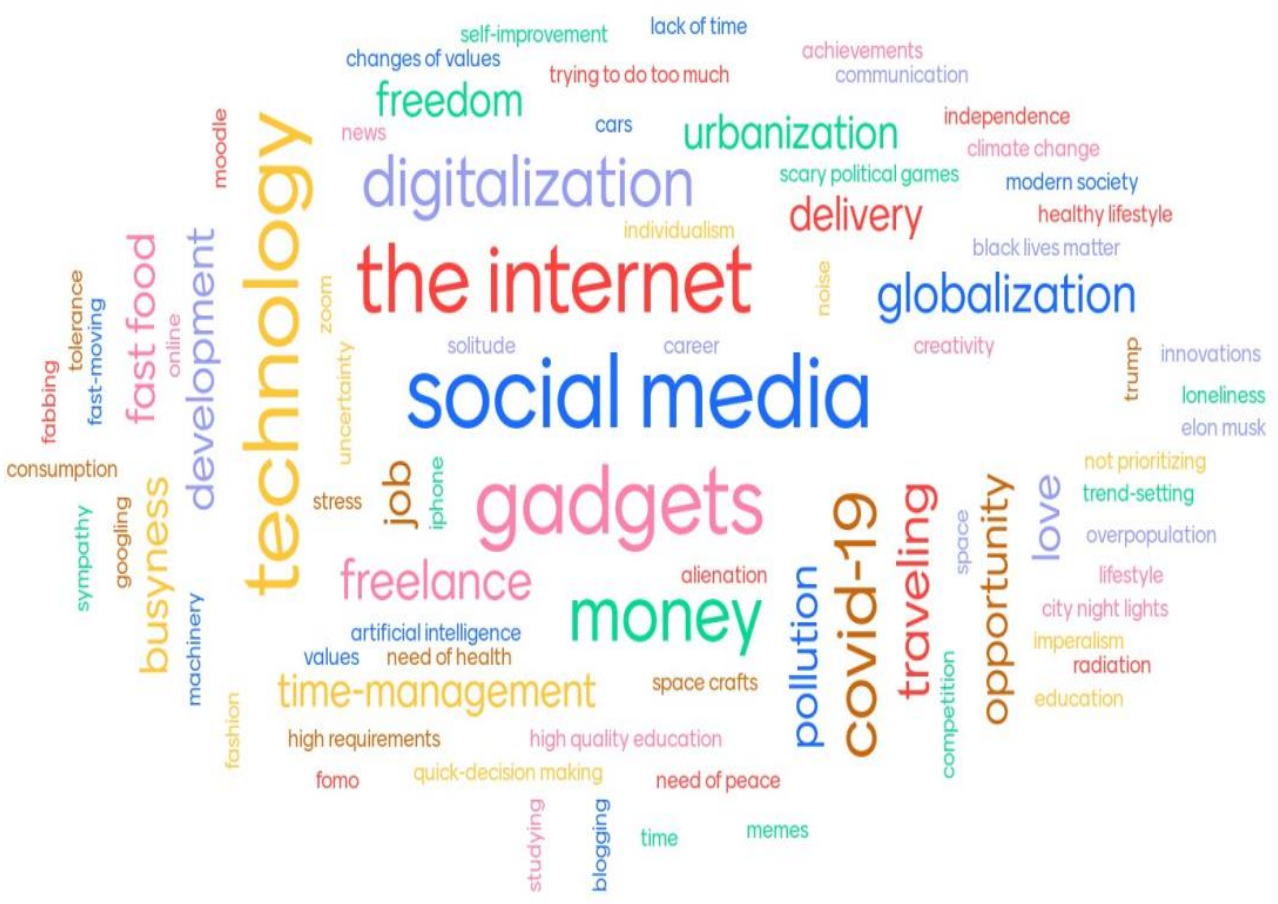

Figure 1. A word-cloud representation of the second-stage associations with the concept MODERN LIFE

III. The third stage deals with realia and the question provided helped to reveal the main connections between Ukrainian realia and their associations. Realia in cultural linguistics are regarded as a culture-specific item or culturally loaded word, which may be treated in general sense as the whole of things peculiar to a certain culture, or as a separate thing found in the national community. Due to the connection with the spheres of human activity and living, they may be distributed into various thematic groups as any language notion. From the point of view of a translator, realia refer to the so-called "non-equivalent vocabulary" which consists of words denoting things or concepts that are nonexistent in the culture of other nations 
(Barkhudarov, 1975: 93, Terekhova, 2018: 107).

The definition of the term "realia" was not given to the students, so they understood this notion in another way. Realia were treated as the facts and objects that are inherent to the present-stage of the development of our culture or is the component of it, as well as things in reality that lead to the hallmarks of political, social, economic life of Ukrainians. On this basis the results obtained in our research showed that the top one among realia is borshch $(7.4 \%)$, which is, perhaps, not surprising, as food realia are one of the most active in the lexical layer of any language. Besides, respondents regarded borshch as modern realis, though on the first and second stages concepts of technology and internet prevail. Obviously, the collocation "Ukrainian realia" served as a stimulus for choosing this answer. The next on the scale are phenomena of EuroMaydan /Maidan (6.2\%) and war (6.2\%). However, it should be noted that according to the definition of realia in a cultural sense as the phenomenon that is peculiar to one cultural and cannot be found in another one, we may state that the term EuroMaydan fits this definition, while war is treated as the phenomenon of the Ukrainian reality. The mention of this word points to the reality of the society and political situation on the East. It is, no doubt, strongly bound with EuroMaydan as the ground for the war actions. Not less interesting is the rest of the answers that we got. They distributed equally on the scale but might be united into thematic groups of Economy: bribery (3.1\%), low economy (3.1\%), progress $(3.1 \%)$, poverty $(3.1 \%)$, instability $(3.1 \%)$, Politics: freedom $(3.1 \%)$, elections $(3.1 \%)$, reform $(3.1 \%)$, independence $(3.1 \%)$, oblast $(3.1 \%)$. Others are connected with the current situation of the state: catastrophe (3.1\%), COVID (3.1\%), FOMO (3.1\%), far away (3.1\%), lack of opportunities $(3.1 \%)$, strange $(3.1 \%)$, young people $(3.1 \%)$ and the essential features of our country: Ukrainian language $(3.1 \%)$, Ukrainian talents $(3.1 \%)$, embroidered shirt $(3.1 \%)$. Further, the line of the war actions - low economy - instability - reforms - lack of opportunities for young people and COVID is clearly seen. The common ground that all of these notions share is interconnection between the economic and political issues that arise protest or interest among the population of Ukraine. Moreover, the obtained data indicate directly to the next stage of our research which is bonded to emotions.

IV. During the fourth stage of the questionnaire students were to answer a question if the meaning of the phrase "Modern Ukrainian Realia" is more negative or positive to their mind. Taking into account the changes that started in 2014 and are currently in progress in Ukraine with all the outcomes in economy and politics, the answers of the students approved that. There were three options to choose: positive, negative and other where respondents could type their own ideas and views on the situation. Among the two options given, negative prevails (50\%), positive has $30 \%$. But the answers that we got like "mostly negative but the growth of patriotism", "hoping for better", "more real" tend to be in the middle of the pie chart. Taking into consideration the age of the respondents, 18-22-year-olds, and understanding that the youth is one of the most active layers of the society with a variety of possibilities, chances and power to change the world they live in, we can state that the current mood is not so optimistic. Among the challenges they meet in modern Ukrainian society are:

- revolutionary actions in the political sphere of the country and antiterroristic operation in the East lasting for almost a decade;

- destabilized economy as an outcome of the previous factor and complicated 
by the pandemic situation leading to the loss of jobs, low salaries, small range of opportunities, absence of confidence in the prosperous future. These factors left impact on the life of the students' parents and the next generation absorbed that point of view and attitudes, reflecting it in their own worldview;

- pandemic situation that boosted the fear of missing out, get infected and in general affects the psychological atmosphere and communication between people bringing disbelief, suspicion, need to keep distance.

\section{Meaning of Modern Ukrainian realia is more negative or positive to your mind?}

86 відповідей

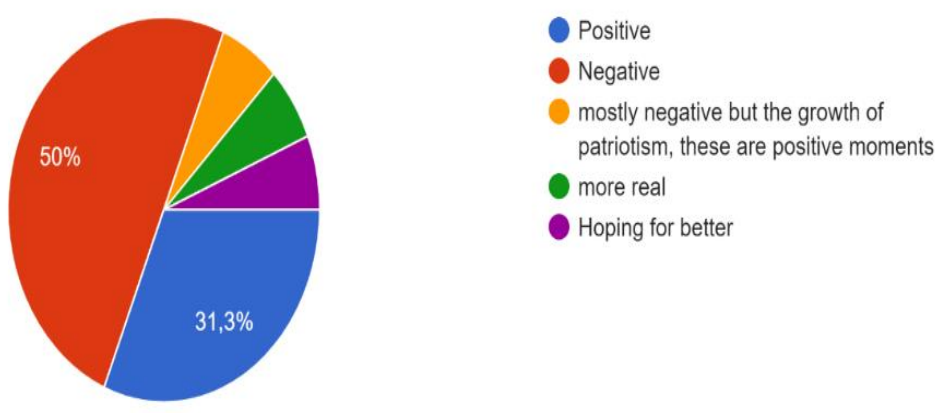

Figure 2. Students' negative or positive perception of the concept MODERN LIFE

$\mathrm{V}$. The next and final stage of the research is construction of the semantic differential method based on scaling different components of modern life suggested by the authors. The suggested components were based on the analysis of sociological, economical and linguistic publications devoted to various aspects of life in modern Ukraine. Thus, the respondents had to decide if the provided components are essential, important but not essential, or not important to their own view of the "Modern Life Concept". The list included 16 components: be wealthy, have a successful career, have Apple gadgets, strong family, be trendy and wear fashionable clothes, child-free lifestyle, own car, good education, self-confidence, travel abroad, active social media life, fast food, healthy food, healthy lifestyle, addictions (smoking, alcohol, drugs, etc.), comfort in everything. The students independently ticked the components according to their beliefs by identifying them as essential, not important or important but not essential.

On the basis of bar graph that we got automatically after data collection the following conclusion is drawn. 


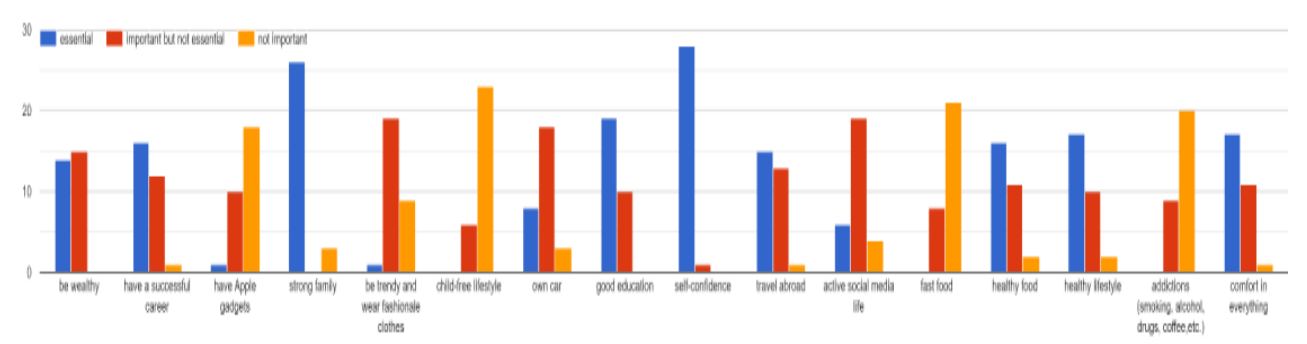

Graph 1. Componential analysis of the concept MODERN LIFE

First, we had to look at the tops of the bars of the given results. The components are arranged in a row. The numbers displayed on the vertical axis represent the number of answers received from the respondents to the components named below the vertical bars.

Next, we subtracted the highest and lowest values displayed above the group of bars and made comparison between the components. With the reference to results, the tallest vertical bar for the value "essential" is observed above "self-confidence" and very close to it is "strong family". This means that spiritual aspect of relations and the virtue that allows to control one's life and trust oneself are of the most importance. There is even a link between them, that means the more confident you are, the more realistic goals you may set and you are confident enough to build a strong and healthy family. In the world where everyone feels the pressure of materialistic things, wealth is considered to be a positive attribute, the tendency to preserve and value essential nonmaterialistic things indicates that feeling comfortable with yourself and others prevails. This is supported by the next tallest "essential" bar above the heading "comfort in everything". This one may be treated broadly - from comfort in everyday routine, which might as well include the aspect of affording to buy the necessary things, have money for vacation, health care to comfort in communication with others, having respect and feeling confident in your skills and position at work. The third tallest bars for "essential" are ascribed on the basis of the voting for "healthy lifestyle" and "healthy food" which are almost of the same value and then components which are also connected - "have good education", "be wealthy", "have a successful career". Healthy lifestyle and healthy food are among top trends in the modern youth lifestyle. Since the replenishment of the social networking sites and blogging in general, lots of influences that promote sports marathons, healthy diet nutrition and everything that keeps you fit affect the conscience of the youth. Moreover, following someone's healthy style keeps you motivated and eases your daily schedule in the aspect that you have no need to search for the recipes to cook healthy food, instead, you can just subscribe to a page or a person and do the same. In addition, the fact that explains that these components gained the same value is that in order to be healthy and lead healthy lifestyle you should eat healthy food. Relatively low results are reflected in the answers "own a car" and "be active in social media". The last one differs as it is not an indicator of the happy life and essential for well-being. The component "own a car" is less essential as leading healthy lifestyle is more about using a bicycle or walking on foot 
rather than using a car. And the least essential are the components "have Apple gadgets" and "be trendy and wear fashionable clothes" that do not correlate with the most valuable component of "self-confidence" and obviously do not add to the comfort of life, but are rather things for the mood and status. The components that did not get the value of "essential" are "fast food", "addictions" and "child-free lifestyle", though these things are found often in today's society, but are treated as negative by the respondents.

It may be concluded that the top component of "self-confidence" is the generalizing one as it includes everything and is built out of healthy lifestyle, prosperous career, successful relation and strong family, be trendy, travel abroad and feel comfort in everything.

Another point to check out is the value "important but not essential". Vertical bars for this category are not equal and is missing in one of the components, i. e. in "strong family", which proves the fact of describing this as an essential characteristic. The same is observed in the most essential component "self-confidence" which has low value for "important but not essential". It means that personal development and one's self is of the utmost importance. The tallest vertical bars for the second value are found above "be trendy and wear fashionable clothes", "own a car" and "active social media life". Now it is clear why these mentioned components had low values in the group "essential". "Be wealthy" and "travel abroad" have lower indicators than the previous, which depend on the person's own worldview, aims and ambitions. The other bars represent the lowest value for components like "child-free lifestyle", "good education", "travel abroad", "healthy food", "fast food", "healthy lifestyle", "comfort in everything", "addictions".

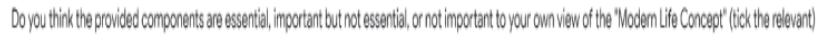

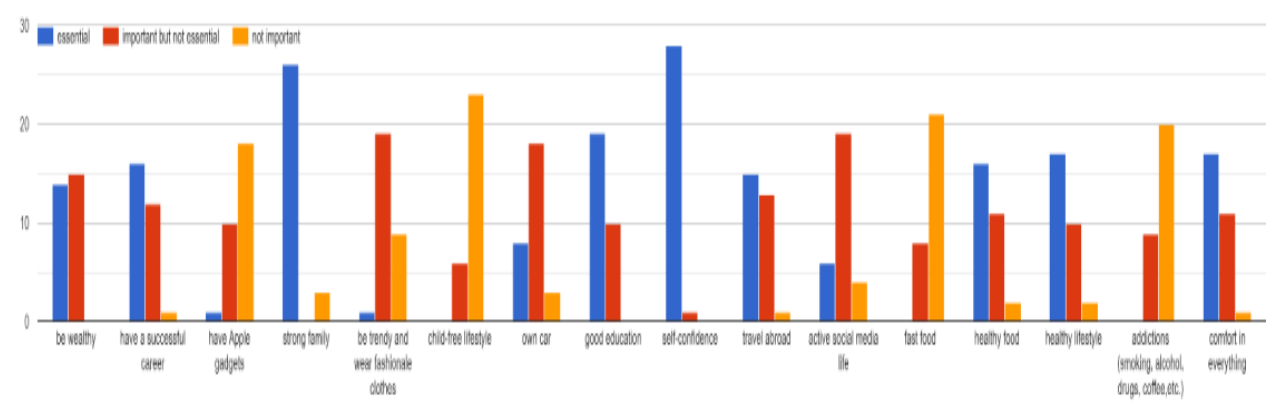

Graph 2. Componential analysis of the concept MODERN LIFE

The last value under analysis is "not important". The respondents highlighted 11 components out of 16 as having low indicators for this value and in 3 of them it is absent at all. This means that "have a successful career", "strong family", "own a car", "travel abroad", "healthy food", "healthy lifestyle", "comfort in everything" have different degree of importance for the respondents, while "be wealthy", "good education", "self-confidence" received 0 answers from the students, however, these components differ in the degree of essentialism. The absence in "be wealthy", "good education" and "self-confidence" shows the desire of the respondents to follow accepted social rules and feel comfortable in the world where the key aspects of a 
successful life are directly connected with the components mentioned. This makes sense, as it correlates with the values analysed above. The tallest bars of "not important" are observed in "child-free lifestyle", "fast food", "addictions" and "have Apple gadgets". These components are not typical for Ukrainian society, in the country where people like homemade dishes and are famous for that, where parents and children have strong bounds and treat family and children as an important aspect of a one's own life. There is a tendency nowadays to own expensive gadgets that is treated by many of the teenagers as a sign of prestige, however, in the more mature youth group we clearly see that it is devoid characteristics to stand in one row with other aspect of true happiness. Hence, addiction gained low value as any conscious person, moreover, educated one, is not aimed at including this component, which can eventually destroy everything from good career to self-confidence, into one's life. What is interesting that the value "not important" is relatively low above the component "be trendy and wear fashionable clothes" that might be revealed in the gender aspect of the respondents as female students prevail in the total number of the students involved.

To summarise the results of the last stage in this research, it is worth noting that the life views of the respondents are fairly positive and among the whole range of the proposed things they choose those that are not connected with money, like good education, comfort, healthy lifestyle, above all - self-confidence. The answer be wealthy is of low rank in respondents' answers and the bar graph demonstrates somewhat different explanations.

\section{Conclusions}

The results of our research show that the linguacultural concept MODERN LIFE functioning in modern Ukrainian worldview expresses cultural features, religious beliefs, economic, political and ideological aspects that matter to the respondent group, Ukrainian students aged 18 to 22 years old. The linguacultural concept is a complex mental construct having its language expression and ethnocultural national specifics. The analysed verbal realizations proved quite productive in representing the concept MODERN LIFE in Ukrainian national language worldview. The study confirmed that the concept MODERN LIFE is ambivalent, but more often negatively marked current phenomenon that has a range of semantic features. The conceptualization of "modern life" in the minds of contemporary young Ukrainians is related to the general scientific, philosophical, economic, social, political and even religious understanding of this phenomenon in the society.

Thus, semantic, paradigmatic, syntagmatic, and phraseological relations of the concept MODERN LIFE can actualize a number of cognitive features on the mental level, which appear to be relevant in the language worldview of the Ukrainian people. Today's meaning of the word-combination "modern life" is changing and supplemented with components related to main meaningful political and economic changes in Ukrainian society and is marked by units denoting information and communication technologies.

Research into individual meanings of words-associations makes it possible to see the specifics of the national worldview of Ukrainian society's young representatives and show their understanding of what ideas, phenomena, realis are 
essential components of the current Ukrainian perception of life.

One of hypothesis of this study concerns the suggestion that modern life is associated with technologies and Internet. It is confirmed as the results show that the concept MODERN LIFE is mainly associated with the notions of "technology/gadgets", "internet/online", "communication", digitalization, money, COVID-19, traveling and time-management.

The scientific hypothesis that COVID-19 occupies a substantial part of it, turns to be rejected as the analysed data show that only $4.6 \%$ of the respondents consider COVID-19 modern life Ukrainian phenomenon that matters and implies people's consideration.

In the case of the experiment with students' personal treatment of life in modern conditions, there is a natural reason for their negative connotation. Approximately $50 \%$ of the respondents treat modern life in Ukraine negatively. The scientific hypothesis that in the national cognitive sphere of young Ukrainians concept MODERN LIFE bears negative connotation is approved by this research.

Among common essential components revealed for the verbal realization of the linguocultural concept MODERN LIFE, as reported by the participants, were "self-confidence" and very close to it is "strong family". The other components ascribed on the basis of the voting are "comfort in everything", "healthy lifestyle" and "healthy food" and then the components "have good education", "be wealthy", "have a successful career". Thus, the proposed hypothesis that wealth and family are dominating parts of the concept structure is partially proved. Family has been a foundational component of national worldview for many centuries. Thus the fact that "strong family" appears to be among the basic in the structure of the concept MODERN LIFE is rater predictable. Nevertheless, wealth turned to be not so crucial for a successful life of a modern Ukrainian student.

Qualitative analysis of the results of the free word association test helped to build the respondents' images of modern Ukrainian hallmarks (borshch, EuroMaydan/Maidan and war) and made it possible to talk about common stereotypes regarding life in Ukraine and national typical characteristics or features in the everyday language consciousness of Ukrainian youth. The other indicated characteristics of the life in modern Ukraine are united into thematic groups of economy (bribery, low economy, progress, poverty, instability), politics (freedom, elections, reform, independence, oblast), current situation of the state (catastrophe, COVID, FOMO, far away, lack of opportunities, strange, young people) and the essential features of our country such as Ukrainian language, Ukrainian talents, embroidered shirt. Ultimately, the obvious interconnection between the economic and political issues that arise protest or interest among the population of Ukraine is established.

According to the conducted study, we came to the conclusion that the following image of the modern life is stereotypical for the Ukrainian language consciousness: technologies and gadgets, internet and communication, strong family and self-realization, borshch, EuroMaydan and war. Analysis of the results showed that modern life for young generation in both male and female minds is perceived in terms of real - digitalised; in terms of attitude - negative; in terms of materialistic values - not materialistic. The linguacultural concept MODERN LIFE appears to be, not radically, but still significantly different in people of the same culture according to their lifestyle, status, field of activity and the amount of information that affects them every day. 
The involvement and analysis of the data from other linguacultures to the research will make it possible to find out more about the universal and culturespecific features of national worldviews. Thus, perspectives for further research into this issue is comparative studies of how the concept MODERN LIFE functions in Ukrainian-speaking and English-speaking language cultures.

\section{References}

Abdikalyk, Kunimzhan and Abitzhanova, Zhanar and Otarbekova, Zhamilya and Kaidarova, Gulyaim and Seidullayev, Gulzhan. 2016. "Concept as the Main Research Object of Cognitive Linguistics". The International Journal of Environmental \& Science Education. 11 (10): 3167-3178.

Barkhudarov, Leonid. S. 1975. Yazyk i perevod: Voprosy obshchey i chastnoy teorii perevoda. Moskva: Mezhdunarodnie otnoshenia.

Blyznyuk, Olena. 2008. "Kontsepty «zhyttia» i «smert»: linhvokulturolohichnyi aspekt (na materiali paremiinoho fondu ukrayinskoyi ta italiiskoyi mov)". PhD diss., Kyiv.

Bobro, Maria. 2020. "The concept LIFE in Ukrainian national linguistic wordview as represented by universal images". Transcarpathian Philological Studies. 13 (1): 12-17. https://doi.org/10.32782/tps2663-4880/2020.13-1.2 [accessed Jan 26 2021].

Ivanova, Iryna. 2008. "Frazeosemantychne pole «zhyttia/smert»: nacionalni stereotypy ta yikh korelyatsii”. PhD diss., Kyiv.

Krasnobaeva-Chorna, Zhanna. 2008. "Kontsept ZHYTTYA v ukrayinskii frazemitsi”. PhD diss., Dnipropetrovsk.

Kubriakova, Elena. Kontseptualnoe prostranstvo yazyka. Sb. nauch. tr., posv. yubileju prof. N. N. Boldyreva. Tambov : Izd-vo TGU im. G. R. Derzhavina.

2019. "Psycholinguistic meaning of the concept of "Faith". PsycholinguisticsPsiholingvistika, 25 (1): 338-362. DOI: 10.31470/2309-1797-2019-25-1-338-362.

Kuzmenko, Yevgeniya. 2016. "Verbal representation of the concept "LIFE" in the English and Russian languages (based on phraseological units)". Bulletin of the Moscow State Regional University, 1: 1-7. DOI: 10.18384/2224-0209-2016-1-732.

Ladyka, Olha. 2017. "Obyektyvatsiya kontseptu AMERICAN DREAM (diakhronnyi pidkhid)". PhD diss., Kyiv.

Ladyka, Olha, Yarema, Oksana. 2019. Lexical Realization of the Concept American Dream in 16-19 ${ }^{\text {th }}$ centuries. Naukovi zapysky Ternopilskoho natsionalnoho pedahohichnoho universytetu imeni Volodymyra Hnatiuka. Seriia: Movoznavstvo, 31 (1): 94-104

Leontev, Aleksei. 2003. Osnovyi Psiholingvistiki. Moskva: Smyisl.

Lozova, Olha. 2007. Psykhosemantyka etnichnoii svidomosti. Kyiv: Osvita Ukrayiny.

Malimon, Liudmyla, Pashkina, Alla. 2019. "Psychosemantic Analysis of the Concept of Manager's Competence". East European Journal of Psycholinguistics. 6 (2): 58-67. DOI: 10.5281/zenodo.3637737.

Petiak, Olena. 2020. "Associative and Gender Aspects of the Emotional Concept of Jealousy in the Ukrainian Linguistic Culture". East European Journal of Psycholinguistics, 7 (1). DOI: 10.29038/eejpl.2020.7.1.pet 
Petrenko, Viktor. 2005. Osnovy psikhosemantiki. S.-Petrsburg: Piter.

Petryshyn, Marta. 2019. "Koncept zhyttia kriz pryzmu latynskykh paremii". Transcarpathian Philological Studies, 11 (2): 37-41. DOI: 10.32782/tps26634880/2019.11-2.6

Sharifian, Farzad. 2017. "Cultural linguistics". Ethnolinguistic, 28: 33-61. DOI: 10.17951/et.2016.28.31.

Skliarenko, Olesia. 2018. "Semantic Structure of Concept «Macht» in German Cultural Studies: Psycholinguistic Aspect”. PSYCHOLINGUISTICS, 24 (2): 292305. DOI: 10.31470/2309-1797-2018-24-2-292-305

Slobodyan, Maryana. 2009. "The method of conceptual analysis in modern cognitive linguistics". Humanitarian Education in Technical Universities, 17: 105115. DOI: 10.18372/2520-6818.17.2315

Stepanov, Yuriy. S. 2001. Konstanty: Slovar russkoi kultury. Moskva: Akademicheskii Proekt.

Siemund, Peter. 2011. Linguistic universals and language variation. Berlin/New York: DE GRUYTER MOUTON.

Terekhova, Diana. 2018. "An Experimental Study of the Lingual Consciousness of Ukrainians and Russians (Dynamic Aspect)". East European Journal of Psycholinguistics, 5 (1): 92-110. DOI: 10.5281/zenodo.1436306.

Torabi, Mohammad. 2002. "Some basic concepts in modern linguistics (T. G. G. approach)". Journal of faculty of letters and humanities (TABRIZ), 45 (182): 29-60.

Wierzbicka, Anna. 1997. Understanding cultures through their key words. Oxford. New York: Oxford University Press. 